\title{
Tumor carcinóide de nasofaringe: relato de caso
}

\author{
Nasopharynx carcinoid tumor: case report
}

Arthur Accioly Rosa, ${ }^{1}$ Erick Santarem da Costa, ${ }^{2}$ Marcos Luiz Bezerra J unior ${ }^{2}$ e Lidia Maria M Cordeiro de Resende ${ }^{3}$

\section{Resumo}

0 artigo descreve 0 caso de um tumor carcinóide de nasofaringe confirmado por análise imuno-histoquímica. A topografia atingida é incomum nesta doença, que tem predileção por sítios gastrointestinais (apêndice íleo-cecal, íleo e reto), e em menor proporção por sítios do trato aerodigestivo, sendo mais comuns os brônquiosea laringe. Paciente de 55 anos apresentouse com obstrução nasal, cefaléia e dor retro-orbitária, com exames complementares que evidenciavam volumosa massa em nasofaringe com extensão para cavidade nasal e base de crânio; sem doença em outra topografia. Foi realizada biópsia, via fossa nasal, cujo laudo histopatológico evidenciou tumor carcinóide de nasofaringe bem diferenciado, extremamente celular e monótomo à $\mathrm{HE}$; ao AE1/AE3 apresentou reatividade para ceratina com formação de DOT paranuclear e cromogramina; S100 e citoqueratina negativos. D evido à irressecabilidade do tumor, foi indicada radioterapia paliativa com $70 \mathrm{G}$ y em 35 frações. 0 resultado clínico foi satisfatório porém sem involução tumoral significativa. A radioterapia pode ser utilizada exclusivamente em tratamento paliativo, porém seus resultados no controle de doença local são ruins.

Palavras-chave: neoplasias nasofaríngeas; carcinoma; radioterapia; diagnóstico; imunohistoquímica. 


\begin{abstract}
This article reports a nasopharynx tumor case diagnosed by immunohistochemic analysis as a carcinoid tumor. The involved site is very uncommon in this disease which is prevalent in gastro-intestial sites (apendicis, ileum, and rectum) and less frequently observed in the aero-digestive tract, predominatly in bronchi and larynx. Thisisa 55 year old white male who presented nasal obstuction, headache and retro-orbitary pain. Examination showed a large mass in the nasopharynx extending to the nasal cavity and skull base; without disease in other sites. The bi opsy was performed through the nasal cavity, and pathologic examination showed a well differentiated, very cellular and HE monotonous carcinoid tumor. Immunohistochemistry was performed with reaction for AE1/AE3, ceratin with D OT formation, cromogramin and paranuclear; S100 and cytokeratin were negative. Because of the its extension, the tumor was considered un resectable, reason why palliative radiation was considered with 70Gy in 35 fractions. The clinical result was acceptable, but without significant local control. Radiotherapy is an option for the palliative treatment of the carcinoid tumor despite its poor results.
\end{abstract}

Key words. nasopharyngeal neoplasms; carcinoma; radiotherapy, diagnosis, immunohistochemistry.

\section{INTRO DUÇÃO}

0 estudo relata o caso de uma neoplasia rara, não havendo casos descritos na literatura com envolvimento exclusivo da nasofaringe. Foi realizada revisão bibliográfica no M edline com as palavras chave: "nasopharynx", "carcinoid", "tumor" e "nasal cavity", isoladas e combinadas, onde identificamos somente três artigos com associação entre o termo carcinóide e a topografia apresentada, porém em apenas um deles confirmava-se tumor carcinóide de cavum com particularidades no diagnóstico. ${ }^{1} 0$ tumor carcinóide faz parte do grupo dos tumores neuroendócrinos e divide-se em 2 subtipos: típicos e atípicos. 0 quadro clínico depende de sua localização e dos níveis de substâncias vasoativas circulantes. Tem como principal sítio primário o trato gastrointestinal (apêndice, íleo e reto), sendo mais rara a ocorrência em sítios extra-intestinais, a saber: pulmão, laringe e outras topografias do trato aerodigestivo. 0 crescimento geralmente é indolente e na maioria dos casos apresentase como um achado incidental. 0 grau de malignidade geralmente relaciona-se com 0 sítio primário e com o tamanho tumoral (T). Q uanto maior $0 \mathrm{~T}$, maior o risco de metástase linfonodal e a distância.

A diferenciação entre tumores típicos e atípicos é importante para avaliar resultados terapêuticos e prognóstico. Esta é feita através da análise histopatológica: número de mitoses, celularidade, necrose focal e pleomorfismo. A maioria dos casos de carcinóide são típicos. Q uando existem características atípicas, há dificuldade em distingui-los de com os paragangliomas. Para estabelecer 0 diagnóstico preciso, também é importante a dosagem de níveis séricos de substâncias vasoativas (ex: serotonina) e seus metabólicos na urina (ex:5-HIAA).

\section{RELATO DO CASO}

\section{IDENTIFICAÇ̃̃O E HISTÓRIA}

H omem, 55 anos, pardo, agricultor, com história de há 18 meses ter iniciado quadro de cefaléia frontal, predominantemente matinal, de média intensidade que respondia à analgesia com antiinflamatórios. Q ueixavase também de dor retro-orbitária bilateral, rinorréia mucóide e obstrução nasal. N ão havia referência a emagrecimento, tabagismo, etilismo ou outras queixas que sugerissem síndrome carcinóide. A única alteração observada ao exame físico foi leve proptose à direita. Encaminhado ao Serviço de Cirurgia de Cabeça e Pescoço do Instituto N acional de Câncer (IN CA) onde após a avaliação dos exames complementares foi concluído tratarse de tumor inoperável. Foi então encaminhado ao Serviço de Radioterapia da mesma Instituição para avaliação de tratamento exclusivo paliativo. 


\section{EXAMES COMPLEMENTARES}

A videofibroscopia do nasofaringe apresentava lesão que infiltrava a base do crânio e pólipos em ambas as cóanas, D e E. A tomografia computadorizada (TC) helicoidal com contraste de seios paranasais evidenciou lesão agressiva predominantemente na nasofaringe à direita, expansiva e captante de contraste, com limites irregulares, tendo o epicentro no seio esfenoidal. Mostrava também destruição dos limites ósseos e extensão supra-selar sem plano de clivagem com os seios cavernosos. Para melhor estadiamento, solicitou-se ressonância magnética (RM) que evidenciou lesão com extensão para partes moles e etmóide, com destruição do trabeculado ósseo; preenchimento das fossas nasais; invasão do esfenóide com destruição do seu muro anterior e extensão também para o seio cavernoso. A lesão envolvia artéria carótida direita intracavernosa e também desviava a haste hipofisária para a esquerda, porém sem compressão do quiasma óptico.

\section{BIÓPSIA DA LESÃO}

Foi realizada biópsia via fossa nasal cujo laudo histopatológico evidenciou tumor carcinóide de nasofaringe bem diferenciado, extremamente celular e monótomo ao $\mathrm{HE}$; ao AE1/AE 3 apresentou reatividade para ceratina com formação de D OT paranuclear e cromogramina; S100 e citoqueratina negativos (Figura 1 ).

Figura 1. RNM em T1, pós-tratamento, apresentando massa sem alterações significativas na sua invasividade

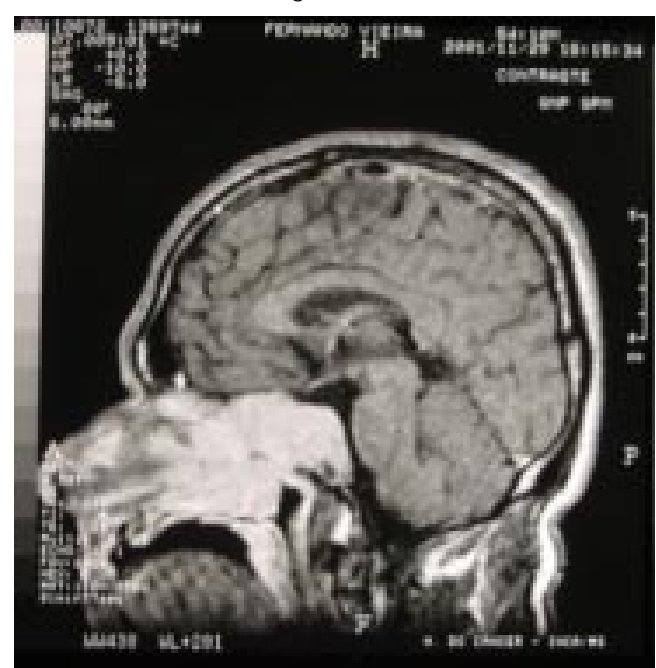

\section{OUTROS EXAMES}

Com o resultado da biópsia levantou-se a hipótese de esta lesão ser metastática, sendo realizados, então, TC de tórax e abdome e colonoscopia. $N$ ão houve evidência de doença nos sítios estudados.

\section{RADIOTERAPIA}

Considerando os melhores resultados no tratamento cirúrgico com radioterapia adjuvante condicionada a parâmetros histopatológicos da peça operatória e a inoperabilidade da lesão, decidiu-se pelo tratamento com radioterapia conformada exclusiva motivada pela localização, tipo histológico e por sua invasividade restrita ao sítio envolvido. Foi administrada dose radical com intenção paliativa, de $70 \mathrm{G}$ y em 35 frações diárias de $2 \mathrm{G}$ y, cinco dias por semana, em nove semanas, de 26/7/01 a 14/9/01. 0 volume tumoral incluiu a nasofaringe e as cadeias de drenagem linfática contíguas, apesar da ausência de comprometimento. Foram distribuídos três campos isocêntricos de fótons de $15 \mathrm{M} \mathrm{v}$, um anterior e dois paralelos opostos latero-laterais com filtros dinâmicos de $60^{\circ}$, superficializador de dose anterior para planificar contorno, com dose prescrita na curva de $86 \%$ e gradiente de $16 \%$. Foram analisados os histogramas dose-volume com limitação de dose em órgão sadios adjacentes, a saber órbitas e cristalinos. D urante as revisões semanais do tratamento observou-se morbidade aguda classificada de acordo com a tabela do Radiation Therapy O ncology Group (RTOG):2 xerostomia grau III, ageusia, conjuntivite, mucosite grau I e radioepitelite grau $\mathrm{I}$.

\section{EVOLUÇão}

Paciente evoluiu com diminuição sintomática principalmente cefaléia e obstrução nasal nos primeiros dois meses. Foi realizada nova RM de controle 80 dias após o término tratamento, que apresentava dissociação clínico-radiológica com aumento da extensão da massa anteriormente, sem mudança do seu comprometimento posterior (Figura 2). Com sete meses de seguimento mantém clínica de dor local com moderada intensidade, que cede ao uso de analgésicos, hipoacusia bilateral e obstrução nasal. Evolui 
também com ganho ponderal discreto e involução da toxicidade aguda do tratamento (xerostomia, ageusia e epitelite).

Figura 2. RNM em T1, pré-tratamento, massa volumosa invadindo clivus, nasofaringe e cavidade nasal

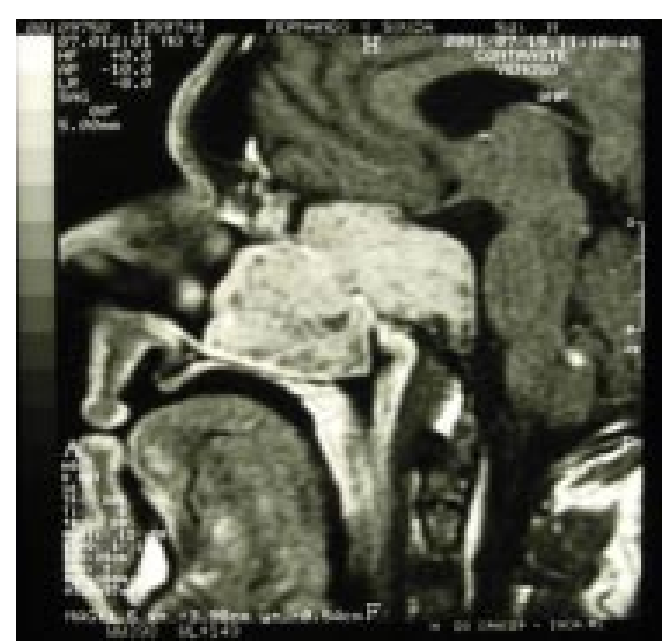

\section{DISCUSSÃO}

O s tumores carcinóides são uma entidade neoplásica que se pensa originária de células neuroendócrinas, ${ }^{3}$ de onde também fazem parte os carcinomas tipo "oat cell". ${ }^{4} \mathrm{~A}$ O rganização M undial de Saúde (O M S) classifica os tumores neuroendócrinos em quatro tipos: tumor carcinóide clássico, tumor carcinóide atípico, carcinoma neuroendócrino de pequenas células e paragangliomas. ${ }^{5,6}$ O s paragangliomas de sítios não intercarotídeos ou vagais acreditava-se possuírem comportamento mais agressivo, com alto potencial maligno quando comparados a outros paragangliomas, ${ }^{7}$ com exceção dos de laringe. ${ }^{8}$ A apresentação dos tumores carcinóide extratrato gastrointestinal é incomum e o diagnóstico diferencial deve ser bastante investigado devido aos poucos casos descritos. O s carcinomas neuroendócrinos ocorrem naturalmente em todos os sítios de cabeça e pescoço, porém os tumores carcinóides, tanto típicos quanto atípicos são encontrados com maior freqüência na laringe. ${ }^{7}$ 0 único caso descrito em literatura de tumor carcinóide de nasofaringe é a descrição de um caso suspeito, que após ressecção e análise da peça operatória concluiu-se tratar de paraganglioma. ${ }^{9} \mathrm{~A}$ peça de biópsia estudada em nosso caso apresentava material adequado, com características de boa diferenciação celular, posicionando a amostra no início do espectro de diferenciação da classificação dos tumores neuroendócrinos como tumor carcinóide clássico.

Pela raridade da doença, a proposta de tratamento para o caso ficou condicionada à experiência descrita em literatura. Pela topografia do tumor, além da maior experiência ser com carcinóides da laringe, decidiu-se pela indicação de tratamento similar a este sítio. 0 tratamento de escolha para os tumores carcinóides de laringe é a ressecção cirúrgica com a radioterapia e quimioterapia assumindo um papel secundário ao grau de diferenciação celular do tumor. ${ }^{7}$ Ao analisar o grau de invasividade e sua topografia, o tumor foi considerado irressecável, limitando as opções terapêuticas do doente. Apesar dos tumores carcinóides serem considerados como parcialmente resistentes à radiação, há alguns relatos de sucesso terapêutico com o uso desta modalidade, principalmente em cenário paliativo. ${ }^{3}$ Foi indicada radioterapia exclusiva com doses radicais, definindo-se a dose observando o necessário para tratamento exclusivo de doença epitelial macroscópica, ou seja, linhagem celular do qual o tumor é originário. ${ }^{5} \mathrm{~A}$ resposta clínica observada, apesar do curto seguimento, foi satisfatória como paliação sintomática. Embora a progressão local tenha sido identificada no exame de imagem, qualitativamente houve melhora subjetiva na qualidade de vida. Um seguimento mais extenso é recomendado para o caso pois a diferenciação do tumor carcinóide podefazêlo responder como tecido de resposta tardia, com conseqüente melhora na progressão local.

\section{CONCLUSÃO}

0 tumor carcinóide na nasofaringe é uma patologia ainda não relatada na literatura médica. Apesar da conclusão quanto ao diagnóstico diferenciado poder suscitar dúvidas, a análise imuno-histoquímica é uma importante arma diagnóstica. A radioterapia pode ser utilizada exclusivamente em tratamento paliativo, porém sua efetividade quanto ao controle local não é absoluta. 


\section{REFERÊN CIAS BIBLIO G RÁFICAS}

1. Siwersson U, Kindblom LG. O ncocytic carcinoid of the nasocavity and carcinoid of the lung in a child. Pathol ResPract 1984;178(6):562-9.

2. Cox JD, StetzJ, PajakTF. Toxicity criteria of the Radiation Therapy O ncology G roup (RTO G) and theE uropean $\mathrm{O}$ rganization for Research and Treatment of $C$ ancer (EORTC). Int J Radiat O ncol Biol Phys 1995;31(5):1341-6.

3. Kulke $M \mathrm{H}, \mathrm{M}$ ayer RJ. Carcinoid tumors. $\mathrm{N}$ Engl J M ed 1999;340(11):858-68.

4. Ibrahim NB, Briggs JC, Corbishley CM . Extrapulmonary oat cell carcinoma. $C$ ancer 1984;54(8):1645-61.

5. Ferlito A, Rosai J. Terminology and classification of neuroendocrine neoplasms of the larynx. ORL J Otorhinolaryngol Relat Spec
1991;53:185.

6. Shanmugaratnan $\mathrm{K}$, editor. World $\mathrm{H}$ ealth O rganizationn hystological classification of tumors: hystological typing of tumors of the upper respiratory tract and ear. 2nd ed. Berlin: Spinger-Verlag; 1991.

7. Weed $D, N$ etervilleJ, M alley B. Paragangliomas of the head and neck. In: $\mathrm{H}$ arisson $\mathrm{L}$, Sessions R, H ong W, editors. $\mathrm{H}$ ead and neck cancer: a multidisciplinary approach. Philadelphia: Lippicont Raven; 1999.

8. Ferlito A, Barnes L, Weng BM . Identification, classification, treatment and prognosis of laryngeal paraganglioma: review of theliteratureand eight new cases. Ann 0 tol Rhinol Laryngol 1994;103:525.

9. Kanoh N, NishimuraY, N akamuraM . Primary nasopharyngeal paraganglioma: a case report. Auris N asus Larynx 1991;18(3):307-14. 